\title{
Music for Hedonia and Eudaimonia During Pandemic Social Isolation
}

\author{
Niels Chr. Hansen ${ }^{1,2}$ \\ ${ }^{1}$ Aarhus Institute of Advanced Studies, Aarhus University, Aarhus, Denmark \\ ${ }^{2}$ Center for Music in the Brain, Aarhus University \& Royal Academy of Music Aarhus/Aalborg, Aarhus, Denmark
}

\begin{abstract}
The pandemic spread of the novel coronavirus and associated COVID-19 disease in 2020 prompted governments around the world to pursue strict containment protocols to minimize contagion risk. Although restrictions were interpreted more strictly in some countries than in others, widespread social isolation resulted on an unseen scale, leading to severe negative mental health consequences such as loss of hope, increased anxiety, stress, depressive symptoms, and sleep disturbance. During this time, while governments were battling the health crisis, musical engagement provided key, individualized coping strategies for laypeople. This was first demonstrated anecdotally in captivating balcony music videos from Italy and Spain and later substantiated in large-scale, multi-country survey studies. This chapter reviews the emerging research literature on music listening and making during pandemic lockdown to establish how music became a compensatory source of hedonic pleasure and how it satisfied the need for eudaimonic meaning in life during socially and psychologically impoverished times.
\end{abstract}

W hen the World Health Organization's (WHO) country office in China first picked up a regional media statement on odd cases of "viral pneumonia" in Wuhan, Hubei province, on the last day of 2019, ${ }^{1}$ not many realized the somberness of this omen of challenging years ahead. Within months, the novel coronavirus, SARS-CoV-2, and the COVID-19 disease that it causes had impacted nearly all communities worldwide leaving a glooming trail of overburdened healthcare systems, premature deaths, and widespread angst in its wake. Devoid of vaccines and scientifically validated treatment regimes, governments worldwide introduced and steadily tightened a wide variety of nonpharmaceutical containment measures. The resulting societal shutdowns were on a hitherto unseen scale. Accompanying deteriorations in mental health and well-being created an urgent need for effective, widely accessible, and lockdown-compatible psychological coping strategies. Active engagement with media content-and especially creative art forms such as music-oftentimes fulfilled this need. Throughout this chapter, the term "coronamusic" will be used to characterize the cultural products resulting from engaging with music during COVID-19 lockdown in ways that make either direct or indirect reference to pandemic life circumstances or the coronavirus itself (cf. Hansen et al., 2021).

The implemented containment measures were documented in comprehensive datasets made available to the public (Desvars-Larrive et al., 2020; Hale et al., 2021; Porcher, 2020; Zheng et al., 2020). Collectively, these research efforts document combinations of: bans on mass gatherings; curfew; cancellations of cultural and sporting events; closures of restaurants, bars, shops, schools, and venues; domestic and international travel restrictions; public testing and surveillance programs; quarantines; face mask mandates; police/military deployment; and postponement of democratic elections. Predictably, financial hardship ensued on the systemic and individual levels, calling for supplementary economic support policies, including wage support, stimulus checks, credit schemes, alongside cuts and deferrals to taxes and fees. While government responses increased most prominently around the pandemic declaration by WHO on 11 March 2020, many of them remained in place far beyond 2020 (see Fig. 1). At the time of writing (September 2021), it remains unclear whether life will ever fully return to

\footnotetext{
1 "Timeline: WHO's COVID-19 response" retrieved from the website of the World Health Organization on 7 April 2021 (https://www.who.int/emergencies/diseases/novel-coronavirus-2019/interactive-timeline).
} 
pre-pandemic norms even once vaccination efforts catch up globally and SARS-CoV-2 has achieved its predicted endemic status (Veldhoen \& Simas, 2021).

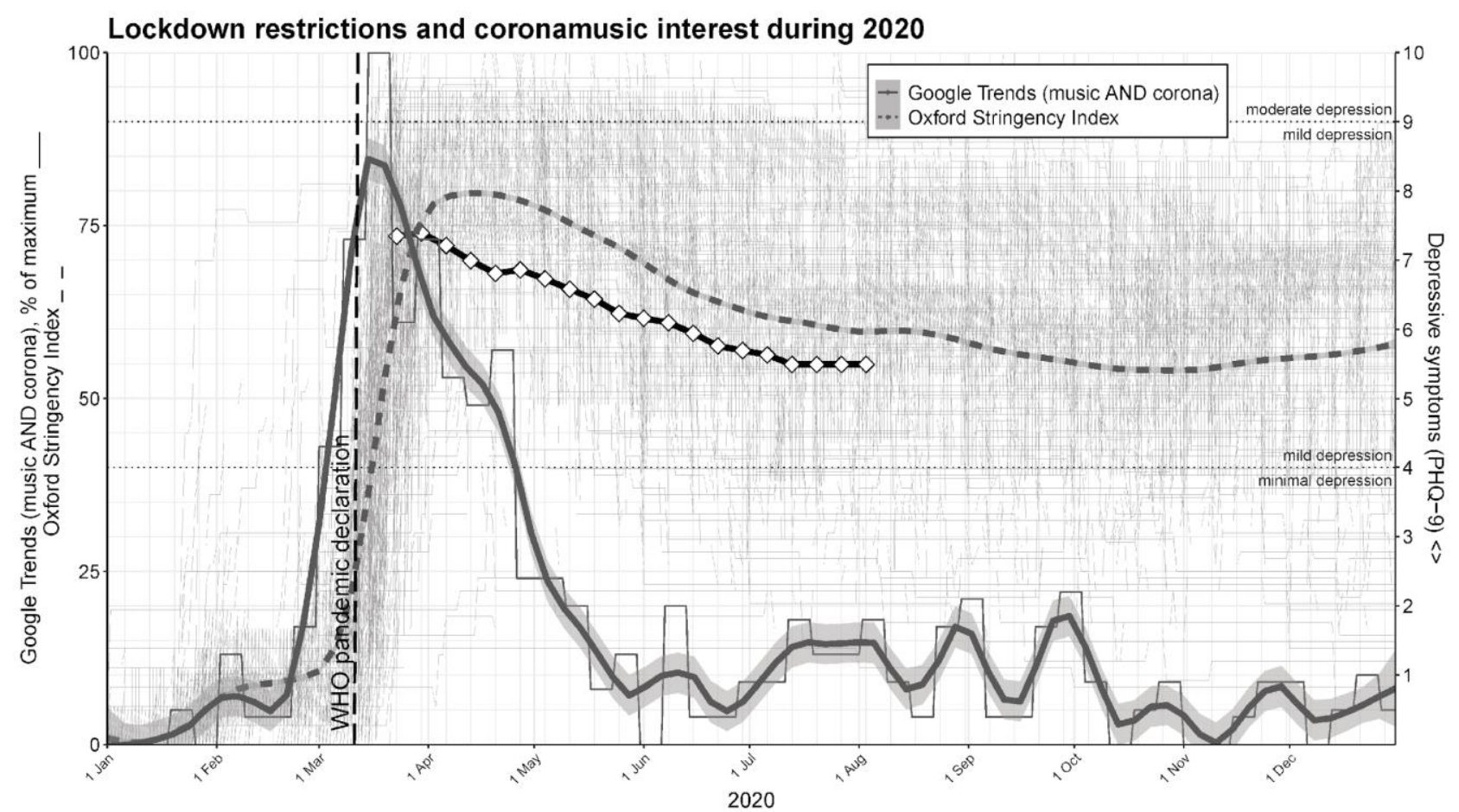

Figure 1. Development in the interest in corona-themed music, mental health, and government restrictions around the world during 2020. Coronamusic interest was quantified via weekly Google Trends data for the search term "music AND corona" (thin, jagged, dark line; sourced on 12 February 2021) fitted with an overlaid LOESS curve (thick dark line with shaded 95\% confidence intervals). Mental health trajectory from 23 March to 3 August 2020 is exemplified with depressive symptoms in the English population as assessed by Fancourt et al. (2021) using the Patient Health Questionnaire (PHQ-9) (diamond shapes). Lockdown intensity was quantified via the stringency index from Oxford COVID-19 Government Response Tracker (Hale et al., 2021) averaged across all 186 featured countries (thick, dashed line). Country-specific stringency indices are also plotted (ultrathin, gray lines). The y-axis simultaneously represents the percentage of maximum search activity for Google trends throughout 2020, depressive symptoms scores, as well as the scale of the stringency index. The SARS-CoV-2 outbreak was formally declared a pandemic by the World Health Organization (WHO) on 11 March 2020 (dashed, vertical line).

These dramatic intrusions upon personal liberty, movement, and social life instigated an accompanying mental health epidemic (e.g., Hossain et al., 2020; Tsamakis et al., 2021; Vindegaard \& Benros, 2020). Psychological adversities included increases in depression, anxiety, stress, panic attacks, irrational anger, impulsivity, somatization disorder, sleep disorders, and emotional disturbance. Pertinent stressors such as social stigma, boredom, feelings of guilt, fear of infection, uncertainty, and financial loss further induced posttraumatic stress symptoms (Hossain et al., 2020). Depressive symptoms in the adult English population $(n>70,000)$ declined slightly as restrictions eased over the summer of 2020, but remained high with consistent averages within the mild depression range (Fancourt et al., 2021) (Fig. 1). Unlike the acute and sometimes long-lasting symptoms of coronavirus disease itself, lockdownrelated psychological health deterioration affected the entire population-not just those who contracted the virus.

During the initial phase of the crisis, governments were understandably preoccupied with urgent medical matters. Hence, the societal collective constituted a key instigator of psychological pressure through enforcement of physical distancing measures whereas steps towards alleviating the negative mental health consequences were largely left to the individual. Many saw themselves with extra time on their hands-either because they were unable to work from home or because they were freed from lengthy commuting times and commitments outside their homes. Mak et al. (2021; also see Eden et al., 2020) demonstrated how people engaged in multifarious leisure activities falling into four overall categories: digital arts and writing, crafts, reading for pleasure, and musical activities. Individuals who were young, highly educated, worried about infection, used emotion- or problem-focused coping 
strategies, or experienced social support were overall more likely to increase their arts engagement during lockdown. Relocation of arts activities to the digital sphere may have instigated opportunities for creative activities across wider socioeconomic spectra.

Musical lockdown activities took various forms from live-streamed concerts (Swarbrick et al., 2021), splitscreen recordings (Hansen et al., 2021), daily rituals of balcony singing and clapping for healthcare workers (Imber-Black, 2020) to virtual raves (Palamar \& Acosta, 2020) and listening parties (Lee \& Kao, 2020). Amateurs and professionals took part as creators and consumers alike via new tele-conferencing and video-editing technologies and well-known social media platforms. On YouTube, Twitter, Facebook, Instagram, and TikTok, the \#coronasongs, \#quarantunes, \#covidance, \#pandemix, and \#songsofcomfort hashtags proliferated. Interestingly, the peak in coronamusic interest appears to predate the peak in containment measures (Fig. 1). This raises the possibility that both psychological struggling and increased musical engagement could be driven by fear of a globally spreading virus before it arrives rather than by tangible experience with viral exposure or containment measures.

In any case, the historical precedence for widespread music-making during prior pandemics (Chiu, 2020) suggests that universal psychological coping mechanisms may be at play (Sarasso et al., 2021). Yet, while videos of Italians and Spaniards singing from their balconies cannot help put a smile on most people's faces, the scientific basis underlying music's allegedly healing powers on the human psyche remains somewhat obscure-both in general terms and in the specific context of an ongoing health crisis. In this regard, sensationalist media reports can be deceiving and certainly cannot stand alone (Deaville \& Lemire, 2021; Hansen et al., 2021).

The current chapter aims to address the following research question: What role did musical activities play in people's psychological coping under pandemic isolation, and to what extent were these behaviors driven by motivations of a hedonic vs. eudaimonic nature? In doing so, I will critically review the emerging research literature on music listening and making during lockdown, zooming in on coping efficacy and moderating factors. Drawing on the contents of a crowdsourced database of coronamusic (Hansen et al., 2021), I will furthermore discuss which musical repertoires were preferably consumed and created.

\section{Pandemic Music Listening}

Objective, consumer-based user statistics and subjective, self-reported measures offer divergent perspectives on the quantitative aspects of pandemic music listening. While aggregated weekly streaming counts of the top-200 songs on Spotify decreased by $12.5 \%$ on average (Sim et al., 2020; Yeung, 2020), YouTube plays for the same artists increased significantly (Sim et al., 2020). These changes were directly associated with declines in mobility (sourced from Google and Apple), to most government restrictions (except for school closures and limits on private gatherings), and to number of COVID-19 cases (but not deaths). Reduced commuting and home confinement may thus have instigated a switch from audio- to video-based platforms (Carlson et al., 2021).

When asked directly, most participants reported increased music listening during lockdown (CabedoMas et al., 2021; Carlson et al., 2021; Ferreri et al., 2021; Fink et al., 2021; Mas-Herrero et al., 2020; Ribeiro et al., 2021a, 2021b; Steinberg et al., 2021; Ziv \& Hollander-Shabtai, 2021)—paradoxically, also for Spotify (Hurwitz \& Krumhansl, 2021). Individual differences are, however, substantial, and some studies found no to little change (Carlson et al., 2021; Krause et al., 2021; Ziv \& Hollander-Shabtai, 2021). Canadian university students deemed music listening the most frequent solitary, extra-curricular activity during lockdown (Finnerty et al., 2021). Potentially, decreased quantitative listening, increased self-reported listening, alongside switching towards video-based platforms could arise from more attentive, meaningful listening modes subject to lower degrees of distraction. This interpretation would be consistent with observations that video-based social media platforms (e.g., YouTube) may be more conducive to emotional contagion than message-based ones (e.g., Twitter) (Rosenbusch et al., 2019). 


\section{Coping efficacy}

The fact that similar increases were reported for many other domestic activities-like watching news and movies, calling friends, cooking, cleaning, and sleeping (Fink et al., 2021; Muñiz-Velázquez et al., 2021; Ziv \& Hollander-Shabtai, 2021) - raises the pertinent question whether changes in musical habits were merely an epiphenomenon of home confinement. Survey studies on qualitative motivations for engagement and perceived coping efficacy suggest that this was not the case. In pandemic times, at least half of the general population used music for coping (Cabedo-Mas et al., 2021; Fink et al., 2021; Kiernan et al., 2021; Martínez-Castilla et al., 2021; Sameer et al., 2020). While active music-making activities like singing and dancing were deemed the most effective (along with music listening), they were also the most ceased (Kiernan et al., 2021). This may have increased the relative appeal of music consumption relative to music creation. By comparison, pandemic TV watching and social media usage were overall negatively associated with well-being (Krause et al., 2021; Muñiz-Velázquez et al., 2021).

Participants in Granot et al.'s (2021) multi-country study ranked the importance of wellbeing goals for coping as follows: (1) enjoyment, (2) venting negative emotions, (3) sense of togetherness, (4) selfconnection, and (5) diversion. While they considered music the most effective activity for achieving enjoyment, venting, and self-connection, music, moreover, provided diversion equally well as entertainment and ranked second after socialization for enhancing togetherness. In a similar vein, Australians found music listening the most effective creative activity (Kiernan et al., 2021) or rated it at least as effective as exercise, sleep, and changing location (Vidas et al.'s, 2021). The emphasis on hedonic factors was substantiated by Fink et al.'s (2020) findings that the motivations for musical engagement showing the strongest increases were enjoyment, mood enhancement, relaxation, and energization. Findings that positive reframing and active coping strategies were strong predictors of musical coping, however, suggest that eudaimonic factors also played a role (Henry et al., 2021). Mas-Herrero et al.'s (2020) participants found music best for coping with psychological distress, outperforming watching series/movies, reading books, and physical exercise. Of particular interest, hours of musical engagement during (but not before) lockdown were negatively associated with distress. Relatedly, Krause et al. (2021) found that life satisfaction was positively associated with music listening, but negatively associated with watching TV/videos/movies at the within-person level. Equivalent negative associations emerged between watching TV and eudaimonic as well as hedonic well-being (MuñizVelázquez et al., 2021). While most people experienced equally strong emotions in response to music during lockdown compared to before, increases were slightly more frequent than decreases-but this was also the case for non-music-induced emotions (Ziv \& Hollander-Shabtai, 2021). Musical activities in children increased during lockdown, and parents used music significantly more for emotion regulation and for connecting socially with their offspring (Cho \& Ilari, 2021; Ribeiro et al., 2021a; Steinberg et al., 2021). Taken together, these results strongly confirm pre-pandemic findings that music listening is capable of effectively enhancing wellbeing (Randall \& Rickard, 2017; Saarikallio, 2011).

\section{Moderating factors}

Whereas COVID-19-specific, contextual factors had limited influence on the perceived efficacy of musical behaviors for wellbeing enhancement, individual factors - such as employment situation (Cabedo-Mas et al., 2021)—showed stronger moderating effects. In general, younger people and those with higher levels of musical training reported greater efficacy (Henry et al., 2021; Martínez-Castilla et al., 2021). These effects were, however, fully mediated by the perceived importance of music (Martínez-Castilla et al., 2021), which was significantly higher in younger and musically trained individuals (cf. Granot et al., 2021). Relatedly, Fink et al. (2021) found this factor to be amongst the six strongest predictors of pandemic coping with music. Fear of infection and of overall pandemic consequences predicted musical engagement for social interaction and for positive affect regulation, respectively (Ferreri et al., 2021). 
Different age groups seemed differentially motivated although effect sizes were modest and the directions remain unclear. One study reported a tendency for the use of music for emotional selfregulation and anxiety reduction to increase with age whereas use of music for loneliness reduction showed the opposite pattern (Martín et al., 2021). Conversely, another survey found that music reduced loneliness with higher efficacy in elderly age groups while also achieving enjoyment with higher efficacy in younger age groups (Granot et al., 2021; Martínez-Castilla et al., 2021).

Use of music as a proxy for social interaction was overall more prominent in people experiencing positive emotions whereas those experiencing negative emotions relied on music for solitary emotion regulation (Fink et al., 2021; see also Ribeiro et al., 2021b). Whereas the latter group were most strongly dissociated on hedonic motivations like distraction, daydreaming, negative emotion venting, comfort, and stress reduction, the former group were most strongly dissociated on eudaimonic motivations like spiritual and aesthetic experience, cultural connection, and identification with the artists and others. Felt connectedness with the artist during live-streamed concerts, however, correlated positively with pandemic-induced stress and could be enhanced by wearing virtual reality headsets (Onderdijk et al., 2021b). Social connection was rated higher when virtual concerts were live-streamed in real-time rather than played back afterwards (Swarbrick et al., 2021). Mas-Herrero et al. (2020) found that individual reward sensitivity (which may be thought of as hedonic susceptibility) fully mediated the negative association between music activities during lockdown and pandemic depression.

Supporting the notion of music as a universal pandemic coping strategy (Chiu, 2021; Sarasso et al., 2021), cross-cultural differences between the countries surveyed were generally small, albeit with a slight tendency for collectivistic cultures to rate efficacy higher than individualistic cultures (Fink et al., 2021; Granot et al., 2021). Gender effects were also negligible (Granot et al., 2021; Henry et al., 2021).

\section{Music selection}

Music selection behavior was affected by lockdown life. Participants reported listening more to happy music, newly discovered music, and music from one's childhood whereas listening to sad music decreased (Ferreri et al., 2021). Selection of happy and novel music was associated with individual inclination towards using music for emotion regulation, happy music was associated with cognitive reappraisal, and sad music with young age. Those who sought music-related activities to mitigate negative emotion listened more to happy music. Analyzing acoustic features accessed through the Spotify API, Hennessy et al. (2021) found that the extent to which people were affected by the pandemic correlated negatively with loudness and energy, but positively with acousticness. Music which university students listened to during lockdown tended to contain lyrics and be in the major mode, albeit with predominantly negative valence (Vidas et al., 2021). The lack of pre-pandemic controls, however, makes it hard to assess how much these behaviors differed from usual listening habits. Survey studies found that $25-31 \%$ had explored new musical styles, and more than half had discovered new musical artists while in lockdown (Cabedo-Mas et al., 2021; Fink et al., 2021). Hurwitz and Krumhansl (2021) collected specific "signature songs" that participants associated with the lockdown period, emphasizing positive, negative, and mixed emotions alongside strong memories and nostalgia.

\section{Nostalgia}

One musical characteristic receiving particular interest was nostalgia. Indeed, media-induced nostalgia has previously been proposed to enhance psychological and subjective wellbeing through both hedonic and eudaimonic mechanisms (Wulf et al., 2018). Yeung (2020) operationalized nostalgia as release dates older than 3 years in 17 trillion Spotify plays in Belgium, France, Italy, Spain, UK, and Sweden in January-July 2020. In addition to seasonal peaks around Christmas (and Swedish Midsummer), nostalgic music consumption increased systematically with peaks around 80 days after lockdown was introduced. The effect of COVID-19 incidence rate was much less pronounced. While listening to older music may have increased, nostalgic-themed Spotify playlists did, however, not exhibit significant increases in 
followers (Sim et al., 2020). As the nostalgia effect eventually declined despite continued lockdowns, Yeung (2020) speculated that nostalgia could be less prominent during later epidemic waves.

Based on self-reports, $36 \%$ declared increasing consumption of nostalgic music (Fink et al., 2021), and $68 \%$ reported having listened to nostalgic music at least weekly during lockdown (Gibbs \& Egermann, 2021). When asked to explain why they had listened to specific nostalgic songs, participants in the latter study provided reasons that typically related to memories of a prior life period (55\%), a significant person or people (34\%), their own identity formation (24\%) or perspectives on life (14\%), a specific event or situation (18\%), a place or travel destination $(12 \%)$, a prior trauma $(8 \%)$, or a musical performance (8\%). Emotional associations with self-selected music were overly positive $(66 \%$ compared to $11 \%$ negative and $19 \%$ mixed) which could be suggestive of coping efficacy.

Beyond the European context, Granot et al. (2021) detected cross-cultural differences. Specifically, nostalgia only mediated the relationship between distress and negatively valenced music in collectivistic but not in individualistic cultures. Such collective nostalgia was enthusiastically cultivated online. During Tim Burgess' more than 750 listening parties, thousands of fans from 150+ countries synchronously listened to past music while partaking in live, interactive commentary together with band members on Twitter (Lee \& Kao, 2020). In addition to the somewhat antiquated practice of listening to entire albums from beginning to end, topics were prominently commemorative with communal sharing of treasured memorabilia and concert memories. Quantitative streaming data, survey responses, and observational studies of online music events thus all allude to the eudaimonic potential of listening to nostalgic music as an approach-related coping behavior during the pandemic. Nostalgic music may moreover have been pursued for hedonic pleasure or distraction (Lee \& Kao, 2020).

\section{Coronamusic}

When music consumption partly migrated from Spotify to YouTube (Sim et al., 2020), some listeners turned towards the topical repertoires of corona-themed music (cf. Hansen et al., 2021). At least 87.5\% of Israelis were exposed to coronamusic videos, with the greatest prominence of humoristic clips followed by splitscreen recordings and performances in empty concert halls and musicians' homes (Ziv \& Hollander-Shabtai, 2021). Thirty-one percent of Spanish respondents enthusiastically followed musical initiatives designed to enhance wellbeing during confinement whereas another $24.2 \%$ were aware of them and had created or participated in some capacity (Cabedo-Mas et al., 2021). Some studies found higher engagement with live-streaming media (Carlson et al., 2021) whereas others found no overall change in watching virtual or recorded concerts (Ferreri et al., 2021). Yet, those who used music to overcome social isolation attended more virtual concerts. In a thematic analysis of YouTube comments in response to eight representative examples of coronamusic videos, Fraser et al. (2021) found a dominance of interaction, unity, resilience, identity, and emotion. With the possible exception of emotion, these qualitative findings seem indicative of eudaimonic listening motivations. Indeed, Fink et al. (2021) concluded that $57 \%$ had developed a moderate-to-extreme interest in coronamusic, and this interest, intriguingly, became the strongest predictor of socio-emotional coping via music. This suggests that tailoring musical practice to contextual factors and developing specialized repertoires may constitute an adaptive psychological strategy for coping through societal crisis.

\section{Pandemic Music Making}

Given the positive wellbeing outcomes of active music making outside of pandemic contexts (Daykin et al., 2018), it seems reasonable to hypothesize that singing and playing of musical instruments underlay crisis-related coping in 2020. Fink et al. (2021) showed that pandemic music listening and making were in fact driven by relatively similar motivations. Tellingly, frequent concert-goers were more likely to make music to cope during lockdown. Even so, people did not overall engage in more instrument playing_-but possibly more singing, less dancing, and less composing (Ferreri et al., 2021). Once again, 
it appears that the primary adaptations in musical behavior were more qualitative than quantitative. Different factors motivated professional and amateur musicians.

\section{Professionals}

The novel coronavirus crisis had obvious repercussions for professional musicians' financial circumstances and psychological well-being (Cohen \& Ginsborg, 2021; Spiro et al., 2020). Many also faced unforeseen challenges managing unfamiliar software for live-streaming and remote teaching (Onderdijk et al., 2021a). MacDonald et al.'s (2021) interviews with members of Glasgow Improvisers Orchestra suggests that joint music making in virtual environments had the capacity to at least partly alleviate negative mental health through social connection, empowerment, and identity validation.

Some affluent popular artists organized and contributed to charity benefit concerts (McIntoch, 2020). Large-scale initiatives like the "One Love Asia Concert" (27 May) and "One World: Together at Home" (18 April) - the latter of which, organized by Global Citizen and curated by Lady Gaga, raised no less than USD 127.9 million-differed from their historical precursors in terms of more abundant distribution channels, greater geographical proximity of beneficiaries, and the intimate use of celebrity homes as concert venues. ${ }^{2}$

Relatedly, music provided an effective way of communicating public health recommendations to populations that were less reachable through traditional news media. Attentiveness and adherence may have increased when messages were combined with humorous mnemonics and carried by an admired artist with whom the audience could readily identify (Lemaire, 2020; Giuffre, 2021). During the pandemic, this emerged in artist-driven, playful hand-washing songs and topically tailored variations of Gloria Gaynor's “I Will Survive," Neil Diamond's “Sweet Caroline," Dolly Parton's “Jolene," and Pinkfong's "Baby Shark." Thus, by allowing the public further into their intimate spheres, celebrity figures were instrumental in strengthening international unity and promoting healthy behavior.

\section{Amateurs}

Amateur musical communities adapted to pandemic life through virtual choirs and ensembles. Switching to virtual format was more pronounced for singing (83\%) and dancing (86\%) than instrumental (60\%) ensembles (Draper and Dingle, 2021). Lack of suitable technology and dedicated funding were indicated as the most common reasons for non-adaptation. Group identification and psychological needs satisfaction were rated significantly lower for virtual than for (retrospectively recalled) face-to-face formats. Yet, the fact that values remained within non-pandemic ranges suggests some coping efficacy of virtual choirs and orchestras.

Daffern et al. (2021) describe three overall modes of virtual joint music making: (i) live-streamed where individuals sing or play with performances live-streamed via social media; (ii) live tele-conferencing where Zoom participants sing or play live to the sounds from a designated leader (with microphones muted); and (iii) multitrack where a collective end-product is mixed offline from solo tracks supplied by individuals. This last format was pioneered in 2009 by the American composer Eric Whitacre who also launched his "Virtual Choir 6: Sing Gently" with 40,0000 singers from 145 countries in 2020. Qualitative analysis of open-ended responses from virtual choir participants highlight six overarching themes: participation practicalities, choir continuity, musical elements, social aspects, wellbeing, and co-creation through singing. The overall experience of taking part in virtual choirs was often negative due to insurmountable technological challenges such as audio latencies and inability to hear one another along with less satisfying musical quality and reduced social connection.

\footnotetext{
${ }^{2}$ See https://www.onelove.asia and https://www.globalcitizen.org/en/content/one-world-together-at-home-impact.
} 
While members of the global shape-note singing community experienced similar grievances, they swiftly and innovatively adapted to changing circumstances (Morgan-Ellis, 2021). By combining multitrack recordings, muted singing via Zoom ("zinging"), joint singing via the low-latency software Jamulus ("jamzinging"), and live-broadcasting themselves singing along with another Facebook Live broadcast ("stringing"), they reconstructed sentiments of musical co-creation, liveness, musical growth, and shared memories. For many choir members, online singing thus formed a much cherished lifeline providing a sense of purpose, identity, and social anchoring during difficult times.

The social aspect of singing was indeed reported as missed the most by around half of $\sim 5,000$ Scandinavian choir singers in a study by Theorell et al. (2020). Professionals were slightly more likely to miss aesthetic experiences, flow, and physical training than amateurs. Norwegians missed social aspects more so than Swedes, which may be ascribed to stricter physical distancing measures in Norway compared to Sweden. Twenty percent of the neighboring Danish population revived their national song treasure (and flow TV) by participating in daily morning and weekly Friday night sing-along programs, catapulting the national songbook into best-seller status (Sørensen et al., 2021; Ulfstjerne, 2020).

The disappointment experienced by many amateur musicians (Daffern et al., 2021; Morgan-Ellis, 2021) and the self-reported quantitative ceasing of singing activities (Kiernan et al., 2021), in fact, suggest that whenever singing at home increased (Ferreri et al., 2021; Fink et al., 2021), this could have been primarily driven by those who did not sing before lockdown. Balcony singing offered a treasured way of restoring individual agency against an incapacitating health disaster (Deaville \& Lemire, 2021). Calvo and Bejarano (2020) argue that because the social messages and community resilience promoted by balcony music typically took priority over musical quality, amateurs and professionals participated side by side. Through interviews, motivations for balcony singing and playing were identified, including entertaining kids, relieving stress, battling loneliness, connecting with neighbors, recruiting followers, expressing affection, celebrating birthdays, solidifying cultural or national identities, commemorating the dead, meeting a social media challenge, and fulfilling one's duty as an artist. Although participation varied widely between countries (from 36\% in Spain to 4\% in Mexico), it was generally associated with stronger feelings of togetherness (Granot et al., 2021). Yet, even in Italy whose balconies were heavily (over-)exposed in early pandemic media reports (Deaville \& Lemire, 2021; Hansen et al., 2021), selfreported behavioral changes towards engagement in outdoors singing or playing were less prominent than overall increases in singing, playing, and composing music at home (Fink et al., 2021). People scoring high on openness to experience were generally more likely to sing or play music during lockdown (Finnerty et al., 2021).

\section{Coronamusic}

Music consumers' demands for corona-themed musical repertoires and opportunities for engagement were effectively met by musical content creators across the physical and virtual spheres. Hansen et al.'s (2021) CORONAMUSIC DATABASE provides a geographically varied corpus of 465 music videos and 254 news reports surveying the coronamusic phenomenon on social media platforms. These corpora were collected through a combination of crowdsourcing and retrospective Google searches via the YouTube domain. The music videos document corona-themed musical repertoire and activities tailored towards both diversion and reflection. Specifically, hedonically motivated coronamusic included balcony singing, livestreamed concerts, virtual raves and listening parties whereas eudaimonically motivated coronamusic was represented, amongst others, by gratitude songs and resilience songs composed for frontline workers and the community at large, respectively.

By coding each database entry on a range of features-including settings, emotions, conflict, movement, joint performance, and musical genre-Hansen and colleagues describe a plethora of innovative musical responses where positively valenced sentiments-like happiness, humor, togetherness, and being moved-were particularly prominently expressed and discussed. This prominence of positive emotions—often presented at a "safe", ironic distance—contrasts starkly with the cruel realities of a 
global pandemic. Future research should aim to investigate the temporal dynamics and psychological causes of this affective incongruence.

\section{Conclusion}

Turning back to the overall research question of this chapter, music evidently played a significant role in psychological coping behavior during pandemic social isolation. This happened through providing solace for the individual, through strengthening collective resilience, and through serving as a valuable replacement for many of the everyday social interactions that people were severely deprived of. The adaptive effects of consuming and creating music were at least comparable to those of other popular creative activities such as crafting and cooking. At times, music's coping efficacy may even have exceeded that of more passive consumption of TV and video streaming services. Hedonic and eudaimonic motivations for pursuing musical activities were concurrently present and may indeed have complemented each other in constructive ways.

While a wide variety of strategies were efficacious for pandemic coping, it remains unclear if the same individuals relied on parallel behavioral strategies, or if the diversity of coronamusic (observed by Hansen et al., 2021, and others) rather reflected individualized coping tactics. This provides a promising avenue for future research endeavors. Constantly evolving technologies for music making and sharing offer novel affordances for individualized mental health interventions which, in turn, call for descriptive alongside prescriptive perspectives on digital engagement with music in a post-pandemic world.

\section{ACKNOWLEDGEMENTS}

The author would like to thank Elvira Brattico for proposing the topic for this chapter. 


\section{REFERENCES}

Cabedo-Mas, A., Arriaga-Sanz, C., \& Moliner-Miravet, L. (2021). Uses and perceptions of music in times of COVID19: a Spanish population survey. Frontiers in Psychology, 11. doi:10.3389/fpsyg.2020.606180

Calvo, K. \& Bejarano, E. (2020). Music, solidarities and balconies in Spain. Interface: A Journal For and About Social Movements, 12(1), 326-332.

Carlson, E., Wilson, J., Baltazar, M., Duman, D., Peltola, H.-R., Toiviainen, P., \& Saarikallio, S. H. (2021). The role of music in everyday life during the first wave of the COVID-19 pandemic: A mixed-methods exploratory study. Frontiers in Psychology, 12. doi:10.3389/fpsyg.2021.647756

Chiu, R. (2020). Functions of music making under lockdown: a trans-historical perspective across two pandemics. Frontiers in Psychology, 11, 616499. doi:10.3389/fpsyg.2020.616499

Cho, E., \& Ilari, B. S. (2021). Mothers as Home DJs: Recorded music and young children's well-being during the COVID-19 pandemic. Frontiers in Psychology, 12. doi:10.3389/fpsyg.2021.637569

Cohen, S., \& Ginsborg, J. (2021). The experiences of mid-career and seasoned orchestral musicians in the UK during the first COVID-19 lockdown. Frontiers in Psychology, 12. doi:10.3389/fpsyg.2021.645967

Daffern, H., Balmer, K., \& Bereton, J. (2021). Singing together, yet apart: the experience of UK choir members and facilitators during the Covid-19 pandemic. Frontiers in Psychology, 12, 624474. doi:10.3389/fpsyg.2021.624474

Daykin, N., Mansfield, L., Meads, C., Julier, G., Tomlinson, A., Payne, A., ... \& Victor, C. (2018). What works for wellbeing? A systematic review of wellbeing outcomes for music and singing in adults. Perspectives in Public Health, 138(1), 39-46. doi:10.1177/1757913917740391

Deaville, J., \& Lemire, C. (2021). Latent cultural bias in soundtracks of Western news coverage from early COVID19 epicenters. Frontiers in Psychology. doi:10.3389/fpsyg.2021.686738

Desvars-Larrive, A., Dervic, E., Haug, N., Niederkrotenthaler, T., Chen, J., Di Natale, A., Lasser, J., Gliga, D. S., Roux, A., Sorger, J., Chakraborty, A., Ten, A., Dervic, A., Pacheco, A., Jurczak, A., Cserjan, D., Lederhilger, D., Bulska, D., Berishaj, D., ... Thurner, S. (2020). A structured open dataset of government interventions in response to COVID19. Scientific Data, 7(1), 285. doi:10.1038/s41597-020-00609-9

Draper, G. \& Dingle, G. A. (2021). "It's not the same": a comparison of the psychological needs satisfied by musical group activities in face to face and virtual modes. Frontiers in Psychology, 12, 646292.

doi:10.3389/fpsyg.2021.646292

Eden, A. L., Johnson, B. K., Reinecke, L., \& Grady, S. M. (2020). Media for coping during COVID-19 social distancing: stress, anxiety, and psychological well-being. Frontiers in Psychology, 11.

doi:10.3389/fpsyg.2020.577639

Fancourt, D., Steptoe, A., \& Bu, F. (2021). Trajectories of anxiety and depressive symptoms during enforced isolation due to COVID-19 in England: a longitudinal observational study. The Lancet Psychiatry, 8(2), 141-149. doi:10.1016/S2215-0366(20)30482-X

Ferreri, L., Singer, N., Mcphee, M., Ripollés, P., Zatorre, R. J., \& Mas-Herrero, E. (2021). Engagement in musicrelated activities during the COVID-19 pandemic as a mirror of individual differences in musical reward and coping strategies. Frontiers in Psychology, 12, 673772. doi:10.3389/fpsyg.2021.673772

Fink, L., Warrenburg, L. A., Howlin, C., Randall, W. M., Hansen, N. C., \& Wald-Fuhrmann, M. (2021). Viral tunes: changes in musical behaviours and interest in coronamusic predict socio-emotional coping during COVID-19 lockdown. Humanities and Social Sciences Communications, 8, 180. doi:10.1057/s41599-021-00858-y

Finnerty, R., Marshall, S., Imbault, C., \& Trainor, L. J. (2021). Music and wellbeing during COVID-19: results from a survey of undergraduate university students. Frontiers in Psychology. doi:10.3389/fpsyg.2021.647402

Fraser, T., Crooke, A. H. D., \& Davidson, J. W. (2021). "Music has no borders": an exploratory study of audience engagement with YouTube music broadcasts during COVID-19 lockdown, 2020. Frontiers in Psychology, 12, 643893. doi:10.3389/fpsyg.2021.643893 
Gibbs, H., \& Egermann, H. (2021). Music-evoked nostalgia and wellbeing during the United Kingdom COVID-19 pandemic: content, subjective effects, and function. Frontiers in Psychology, 12, 647891.

doi:10.3389/fpsyg.2021.647891

Giuffre, L. (2021). Handwashing Hits-Getting Cross-Generational Listeners to Rock during the Pandemic. Rock Music Studies, 8(1), 53-64. doi:10.1080/19401159.2020.1852771

Granot, R., Spitz, D., Cherki, B., Loui, P., Timmers, R., Schaefer, R., Vuoskoski, J., Soares-Quadros, J., Cardenas-Soler, R., Li, S., Lega, C., La Rocca, S., Cecilia-Martinez, I., Tanco, M., Marchiano, M., Martinez-Castilla, P., Perez-Acosta, G., Martínez-Ezquerro, J. D., Gutierrez-Blasco, I., Jimenez-Dabdoub, L., Coers, M., Treider, J. M., Israel, S., \& Greenberg, D. (in press). "Help! I need somebody": music as a global resource for obtaining wellbeing goals in times of crisis. Frontiers in Psychology. doi:10.3389/fpsyg.2021.648013

Hale, T., Angrist, N., Goldszmidt, R., Kira, B., Petherick, A., Phillips, T., ... \& Tatlow, H. (2021). A global panel database of pandemic policies (Oxford Covid-19 Government Response Tracker). Nature Human Behaviour, 5 , 529-538. doi:10.1038/s41562-021-01079-8

Hansen, N.C., Treider, J. M. G., Swarbrick, D., Bamford, J. S., Wilson, J., \& Vuoskoski, J. K. (2021). A crowd-sourced database of coronamusic: documenting online making and sharing of music during the COVID-19 pandemic. Frontiers in Psychology. doi:10.3389/fpsyg.2021.684083

Henry, N., Egermann, H., \& Kayser, D. (2021). Music in mood regulation and coping orientations in response to COVID-19 lockdown measures within the United Kingdom. Frontiers in Psychology.

doi:10.3389/fpsyg.2021.647879

Hossain, M. M., Tasnim, S., Sultana, A., Faizah, F., Mazumder, H., Zou, L., McKyer, E. L. J., Ahmed, H. U., \& Ma, P. (2020). Epidemiology of mental health problems in COVID-19: a review. F1000Research, 9, 636. doi:10.12688/f1000research.24457.1

Hurwitz, E. R., \& Krumhansl, C. L. (2021). Shifting listening niches: effects of the COVID-19 pandemic. Frontiers in Psychology, 12. doi:10.3389/fpsyg.2021.648413

Imber-Black, E. (2020). Rituals in the time of COVID-19: imagination, responsiveness, and the human spirit. Family Process, 59(3), 912-921. doi:10.1111/famp.12581

Janicke-Bowles, S. H., Rieger, D., and Connor, W. (2019). Finding meaning at work: the role of inspiring and funny YouTube videos on work-related well-being. J. Happ. Stud. 20, 619-640. doi:10.1007/s10902-018-9959-1

Kiernan, F., Chmiel, A., Garrido, S., Hickey, M. \& Davidson, J. W. (2021). The role of artistic creative activities in navigating the COVID-19 pandemic in Australia. Frontiers in Psychology, 12, 696202.

doi:10.3389/fpsyg.2021.696202

Krause, A. E., Dimmock, J., Rebar, A. L., \& Jackson, B. (2021). Music listening predicted improved life satisfaction in university students during early stages of the COVID-19 pandemic. Frontiers in Psychology, 11. doi:10.3389/fpsyg.2020.631033

Lee, W., \& Kao, G. (2020). "You know you're missing out on something": collective nostalgia and community in Tim's Twitter Listening Party during COVID-19. Rock Music Studies, 8(1), 36-52.

doi:10.1080/19401159.2020.1852772

Lemaire, E. C. (2020). Extraordinary times call for extraordinary measures: the use of music to communicate public health recommendations against the spread of covid-19. Canadian Journal of Public Health, 111, 477-479. doi:10.17269/s41997-020-00379-2

Löwe, B., Kroenke, K., Herzog, W., \& Gräfe, K. (2004). Measuring depression outcome with a brief self-report instrument: sensitivity to change of the Patient Health Questionnaire (PHQ-9). Journal of Affective Disorders, 81, 61-66. doi:10.1016/S0165-0327(03)00198-8

MacDonald, R. A, Burke, R. L., De Nora, T., Donohue, M. S., \& Birrell, R. (2021). Our virtual tribe: sustaining and enhancing community via online music improvisation. Frontiers in Psychology, 11, 623640. doi:

10.3389/fpsyg.2020.623640 
Mak, H. W., Fluharty, M., \& Fancourt, D. (2021). Predictors and impact of arts engagement during the COVID-19 pandemic: analyses of data from 19,384 adults in the COVID-19 social study. Frontiers in Psychology, 12. doi:10.3389/fpsyg.2021.626263

Martín, J. C., Ortega-Sánchez, D., Miguel, I. N., \& Martín, G. M. G. (2021). Music as a factor associated with emotional self-regulation: A study on its relationship to age during COVID-19 lockdown in Spain. Heliyon, 7(2), e06274. doi:10.1016/j.heliyon.2021.e06274

Martínez-Castilla, P. Gutiérrez-Blasco, I., Spitz, D. H., \& Granot, R. (2021). The efficacy of music for emotional wellbeing during the COVID-19 lockdown in Spain: an analysis of personal and context-related variables. Frontiers in Psychology. doi:10.3389/fpsyg.2021.647837

Mas-Herrero, E., Singer, N., Ferreri, L., McPhee, M., Zatorre, R., \& Ripolles, P. (2020, December 22). Rock'n'roll but not sex or drugs: music is negatively correlated to depressive symptoms during the COVID-19 pandemic via reward-related mechanisms. PsyArXiv. doi:10.31234/osf.io/x5upn

McIntosh, H. (2021). Charity benefit concerts and the One World: Together at Home event. Rock Music Studies, 8(1), 76-82. doi:10.1080/19401159.2020.1852773

Morgan-Ellis, E. M. (2021). "Like pieces in a puzzle”: online sacred harp singing during the COVID-19 pandemic. Frontiers in Psychology, 12, 746. doi:10.3389/fpsyg.2021.627038

Muñiz-Velázquez, J. A., Gómez-Baya, D., \& Lozano Delmar, J. (2021). Exploratory study of the relationship between happiness and the rise of media consumption during COVID-19 confinement. Frontiers in Psychology, 12. doi:10.3389/fpsyg.2021.566517

Oliver, M. B., Raney, A. A., Slater, M. D., Appel, M., Hartmann, T., Bartsch, A., et al. (2018). Self-transcendent media experiences: taking meaningful media to a higher level. J. Commun., 68, 380-389. doi:10.1093/joc/ jqx020

Onderdijk, K. E., Acar, F., \& Van Dyck, E. (2021a). Impact of lockdown measures on joint music making: playing online and physically together. Frontiers in Psychology, 642713. doi:10.3389/fpsyg.2021.642713

Onderdijk, K. E., Swarbrick, D., Van Kerrebroeck, B., Mantei, M., Vuoskoski, J. K., Maes, P. J., \& Leman, M. (2021b). Livestream experiments: the role of COVID-19, agency, presence, and social context in facilitating social connectedness. Frontiers in Psychology, 12, 1741. doi:10.3389/fpsyg.2021.647929

Palamar, J. J., \& Acosta, P. (2020). Virtual raves and happy hours during COVID-19: new drug use contexts for electronic dance music partygoers. International Journal of Drug Policy, 102904. doi:10.1016/j.drugpo.2020.102904

Porcher, S. (2020). Response2covid19, a dataset of governments' responses to COVID-19 all around the world. Scientific Data, 7(1), 1-9. doi:10.1038/s41597-020-00757-y

Randall, W. M., \& Rickard, N. S. (2017). Reasons for personal music listening: a mobile experience sampling study of emotional outcomes. Psychology of Music, 45(4), 479-495. doi:10.1177/0305735616666939

Ribeiro, F. S., Janzen, T. B., Passarini, L., \& Vanzella, P. (2021a). Exploring changes in musical behaviors of caregivers and children in social distancing during the COVID-19 outbreak. Frontiers in Psychology, 12. doi:10.3389/fpsyg.2021.633499

Ribeiro, F. S., Lessa, J. P., De Oliveira, G. A. D., \& Santos, F. H. (2021b). Music listening in times of COVID-19 outbreak: a Brazilian study. Frontiers in Psychology. doi:10.3389/fpsyg.2021.647473

Saarikallio, S. (2011). Music as emotional self-regulation throughout adulthood. Psychology of Music, 39(3), 307327. doi:10.1177/0305735610374894

Hennessy, S., Sachs, M., Kaplan, J., \& Habibi, A. (2021). Music and mood regulation during the early-stages of the COVID-19 pandemic. OSF preprints. doi:10.31219/osf.io/ma85z

Rosenbusch, H., Evans, A. M., \& Zeelenberg, M. (2019). Multilevel emotion transfer on YouTube: disentangling the effects of emotional contagion and homophily on video audiences. Social Psychological and Personality Science, 10(8), 1028-1035. doi:10.1177/1948550618820309 
Sameer, A. S., Khan, M. A., Nissar, S., \& Banday, M. Z. (2020). Assessment of mental health and various coping strategies among general population living under imposed COVID-lockdown across world: a cross-sectional study. Ethics, Medicine and Public Health, 15, 100571. doi:10.1016/j.jemep.2020.100571

Sarasso, P., Ronga, I., Neppi-Modona, M., \& Sacco, K. (2021). The role of musical aesthetic emotions in social adaptation to the Covid-19 pandemic. Frontiers in Psychology, 12. doi:10.3389/fpsyg.2021.611639

Sim, J. and Cho, D- and Hwang, Y. \& Telang, R. (2020). Virus shook the streaming star: estimating the COVID-19 impact on music consumption. SSRN Electronic Journal. doi:10.2139/ssrn.3649085

Spiro, N., Perkins, R., Kaye, S., Tymoszuk, U., Mason-Bertrand, A., Cossette, I., Glasser, S., \& Williamon, A. (2020). The effects of COVID-19 lockdown 1.0 on working patterns, income, and wellbeing among performing arts professionals in the United Kingdom (April-June 2020). Frontiers in Psychology, 11.

doi:10.3389/fpsyg.2020.594086

Steinberg, S. Liu, T., \& Miriam D. Lense, M. D. (2021). Musical engagement and parent-child attachment in families with young children during the Covid-19 pandemic. Frontiers in Psychology, 12.

doi:10.3389/fpsyg.2021.641733

Swarbrick, D., Siguelnitzky, N. G., Seibt, B., \& Vuoskoski, J. K. (2021). Corona soncerts: the effect of virtual concert characteristics on social connection and kama muta. Frontiers in Psychology. doi:10.3389/fpsyg.2021.648448

Sørensen, J. F., Baunvig, K. F., \& Andersen, P. B. (2021). Håndvask og fællessang: ritualer og ritualiserede handlinger i coronaens tid. Religionsvidenskabeligt Tidsskrift, 72, 116-136.

Theorell, T., Kowalski, J., Theorell, A. M. L., \& Horwitz, E. B. (2020). Choir singers without rehearsals and concerts? A questionnaire study on perceived losses from restricting choral singing during the Covid-19 pandemic. Journal of Voice. doi:10.1016/j.jvoice.2020.11.006

Tsamakis, K., Tsiptsios, D., Ouranidis, A., Mueller, C., Schizas, D., Terniotis, C., Nikolakakis, N., Tyros, G., Kympouropoulos, S., Lazaris, A., Spandidos, D. A., Smyrnis, N., \& Rizos, E. (2021). COVID-19 and its consequences on mental health. Experimental and Therapeutic Medicine, 21(3), 1. doi10.3892/etm.2021.9675

Ulfstjerne, M. A. (2020). Songs of the pandemic. Anthropology in Action, 27(2), 82-86.

doi:10.3167/aia.2020.270213

Veldhoen, M., \& Simas, J. P. (2021). Endemic SARS-CoV-2 will maintain post-pandemic immunity. Nature Reviews Immunology, 21, 131-132. doi:10.1038/s41577-020-00493-9

Vidas, D., Larwood, J. L., Nelson, N. L., \& Dingle, G. A. (2021). Music listening as a strategy for managing COVID-19 stress in first-year university students. Frontiers in Psychology. doi:10.3389/fpsyg.2021.647065

Vindegaard, N., \& Benros, M. E. (2020). COVID-19 pandemic and mental health consequences: systematic review of the current evidence. Brain, Behavior, and Immunity, 89, 531-542. doi:10.1016/j.bbi.2020.05.048

Wulf, T., Rieger, D., \& Schmitt, J. B. (2018). Blissed by the past: Theorizing media-induced nostalgia as an audience response factor for entertainment and well-being. Poetics, 69, 70-80. doi:10.1016/j.poetic.2018.04.001

Yeung, T. Y. (2020). Did the COVID-19 pandemic trigger nostalgia? Evidence of music consumption on Spotify. SSRN Electronic Journal, 3678606. doi:10.2139/ssrn.3678606

Zheng, Q., Jones, F. K., Leavitt, S. V., Ung, L., Labrique, A. B., Peters, D. H., Lee, E. C., Azman, A. S., \& HIT-COVID Collaboration (2020). HIT-COVID, a global database tracking public health interventions to COVID-19. Scientific Data, 7, 286. doi:10.1038/s41597-020-00610-2

Ziv, N., \& Hollander-Shabtai, R. (2021). Music and COVID-19: changes in uses and emotional reaction to music under stay-at-home restrictions. Psychology of Music. doi:10.1177/03057356211003326 
14 / 13 